\title{
Assessing Problematic Facebook Use: Psychometric Properties of the Polish Version of Facebook Intrusion Questionnaire
}

Agata Błachnio ( $\sim$ gatta@kul.pl )

John Paul II Catholic University of Lublin: Katolicki Uniwersytet Lubelski Jana Pawla II https://orcid.org/0000-0002-2384-2396

Aneta Przepiórka

John Paul II Catholic University of Lublin: Katolicki Uniwersytet Lubelski Jana Pawla II

Andrzej Cudo

John Paul II Catholic University of Lublin: Katolicki Uniwersytet Lubelski Jana Pawla II

Rachel A. Elphinston

The University of Queensland

\section{Research}

Keywords: Facebook Intrusion Questionnaire, Facebook addiction, Problematic Facebook use, Validation, Factor analysis

Posted Date: May 24th, 2021

DOI: https://doi.org/10.21203/rs.3.rs-535400/v1

License: (c) (i) This work is licensed under a Creative Commons Attribution 4.0 International License. Read Full License 


\section{Abstract}

Background

Facebook is used for work, entertainment and communication. However, there is potential for problematic or addictive use which can cause significant mental and physical health problems. The Facebook Intrusion Questionnaire (FIQ; Elphinston \& Noller, 2011) is one of the most widely used measures of problematic Facebook use. However, no previous study has validated this measure in a Polish population.

Methods

The study aims to validate the Polish adaptation of FIQ. Five large samples of Polish Facebook users $(N=12,753 ; M$ age $=21$ years; $66 \%$ female $)$ were used to examine the psychometric properties of the Polish version of the FIQ.

Results

An exploratory and confirmatory factor analysis provided support for a unidimensional factor structure $\left(\chi^{2}(16)=199.53, p<0.001 ; \mathrm{RMSEA}=0.042 ; \mathrm{SRMR}=\right.$ $0.022 ; \mathrm{CFI}=0.950$ ). Item response theory showed that the adapted FIQ items had adequate discrimination and information levels.

Conclusion

The Polish version of the FIQ showed good internal consistency and adequate construct validity. Overall, the findings suggest that the FIQ is a reliable and valid measure for use in the Polish population.

\section{Introduction}

Facebook is one of the most popular social networking sites with more than one million users every day (Błachnio, Przepiorka, et al., 2018) (Facebook, 2020). It is used in many aspects of life, including work, entertainment or communication. However, there is a down side to Facebook use. Facebook intrusion (Elphinston \& Noller, 2011) also referred to as problematic Facebook use (Lee-Won et al., 2015) and Facebook addition (Andreassen et al., 2012) is defined as a losing control over Facebook use and having a heavy desire to use it that causes negative consequences (Brailovskaia \& Margraf, 2017).

Facebook intrusion is strongly associated with Internet addiction (Bendayan \& Blanca, 2019), problematic mobile phone use (Bendayan \& Blanca, 2019), fear of missing out (Bendayan \& Blanca, 2019) (Agata Błachnio \& Przepiórka, 2018) as well as phubbing (Bendayan \& Blanca, 2019). There is also a wealth of research that suggests problematic Facebook usage has a negative impact on an individual's mental health and interpersonal relationships. It has been positively related to depression (A. Błachnio et al., 2015) (Bendayan \& Blanca, 2019)and negative affect ( Błachnio et al., 2017); low self-esteem (Błachnio, Przepiorka, Benvenuti, et al., 2016); narcissism ( Błachnio, Przepiorka, \& Rudnicka, 2016); loneliness (Błachnio, Przepiórka, et al., 2018); romantic disengagement (Saeed Abbasi, 2018), jealousy and dissatisfaction (Elphinston \& Noller, 2011).

Addiction to Facebook and associated symptoms are currently assessed with self-report measures. The Facebook Intrusion Questionnaire FIQ (Elphinston \& Noller, 2011) is one of the most widely used reliable and valid questionnaires. However, no study to date has evaluated the reliability and validity of a Polish version of the scale. The aim of this study was to validate a Polish adaptation of FIQ. The English version of the FIQ was translated to Polish and its psychometric properties were assessed using samples from several studies conducted among Polish Facebook users. Specifically, the factor structure, reliability, and criterion-related validity was investigated. As approaches to assessment of Internet-based addictions continue to emerge, it is important that clinicians use culturally-appropriate validated measures of Facebook addiction.

\section{Methods}

\section{Sample}

The total sample comprised 12,753 individuals ranging in age from 16 to 70 years $(M=21.48, S D=6.95) ; 8452(66.27 \%)$ of the participants were women. The mean age of female and male participants was comparable (female: $M=21.30$ years, $S D=6.27$; male: $M=21.85$ years, $S D=8.11$ ). We invited individuals of secondary and high schools, and colleges or universities in several main cities of Poland to take part in the study. Eligibility criteria included participants having a Facebook account. It should be noted that, despite the age requirement for setting up a Facebook account, there were individuals who were under 16 years of age who had their own Facebook account. These individuals were included in the study.

For the factor structure and reliability analyses, the total sample was used. For criterion-related validity analyses, the five subsamples from the total sample were used. More specifically, the criterion-related validity analyses included the following number of participants: subsample 1-662 participants (422 women; age: $M=21.06, S D=6.26$ ); subsample 2-290 participants (234 women; age: $M=22.95, S D=2.26$ ); subsample $3-857$ participants (785 women; age: $M=$ $19.61, S D=2.58$ ); subsample $4-131$ participants (88 women; age: $M=21.05, S D=2.05$ ) who played video games in the last year; and subsample $5-47$ participants (20 women; age: $M=20.32, S D=4.07$ ) who were receiving alcohol and drug treatment. In subsample 5 , individuals receiving alcohol and drug treatment included young individuals with alcohol and drug diagnoses according to the ICD 10 (WHO, 1993) and no other diagnosis indicating psychotic and neurological disorders. These individuals were under the care of an addiction treatment centres in Mazowieckie and Lubuskie voivodships. In addition, individuals of similar age and gender as individuals in the treatment group were selected from total sample for the control group $(N=47,20$ women; age: $M=$ $20.36, S D=4.01)$. Individuals in control group currently used no drugs and did not have addiction diagnosis according to the ICD 10 (WHO, 1993$)$. Participation 
in the study was voluntary and participants were assured that their responses were anonymous. All the procedures applied were in accordance with the ethical standards of the responsible committee on human experimentation (institutional and national) and with the Helsinki Declaration of 2005.

\section{Measures}

\section{Facebook Intrusion Questionnaire and approach to translation}

The Facebook Intrusion Questionnaire FIQ (Elphinston \& Noller, 2011) consists of eight items. Participants are asked to rate the items using a 7-point scale, from 1 - strongly disagree, to 7 - strongly agree. Higher scores reflect greater intensity of problematic Facebook use. The questionnaire has good psychometric properties, with Cronbach's alpha equal 0.84 (Agata Błachnio et al., 2017). The questionnaire was also used in another study in Poland, designed to investigate problematic Facebook use (e.g., Błachnio et al., 2015 - Cronbach's alpha equal 0.92; Cudo et al., 2020 - Cronbach's alpha equal 0.85).

Back translation procedure was used when translating the English measure into Polish. Two main authors translated the questionnaire and after that, we compare two versions of the translation. The translated Polish version was then sent to a person who is a native speaker of both Polish and English language. He translated our Polish version into English. Then, we checked the original English version and the Polish version.

\section{Other measures}

The Problem Videogame Playing Questionnaire (Tejeiro et al., 2015), which has been adapted to Polish was used to assess gaming addiction. It comprises nine statements rated by subjects using a dichotomous scale. A greater number of positive responses provided by a subject corresponds with a stronger compulsion to play games. Because of its high clinical accuracy, the questionnaire is one of the best tools currently applied in research into Internet Gaming Disorder (King et al., 2013). The questionnaire has adequate psychometric properties: Cronbach's alpha equals 0.69.

The Problematic Internet Use Test (Hawi et al., 2015) which is a polish adaptation of Kimberly Young's Internet Addiction Test was used to assess Internet addiction. It consists of 22 items in which subjects provide answers on a 6-point scale. It has good psychometric properties: Cronbach's alpha equals 0.935 ; discriminatory power of the items in the range from 0.40 to 0.70 ; and split-half reliability of 0.95 with correlation between the halves amounting to 0.91 .

The Facebook Intensity Scale (Ellison et al., 2007) consists of eight items which measure the intensity and frequency of Facebook usage as well as emotional attitude to Facebook and its impact on daily activities. Responses are given on a Likert scale from 1 - strongly disagree to 5 - strongly agree. Higher scores indicate greater involvement in Facebook use. Cronbach's alpha for the Polish version was 0.78.

The Bergen Facebook Addiction Scale (BFAS) (Andreassen et al., 2012) has been validated by (Atroszko et al., 2017). The scale includes six items which are based on addiction components described by (Griffiths, 2005). Responses are given on a Likert scale from 1 - very rarely to 5 - very often. In a previous study (Atroszko et al., 2017), the Cronbach's alpha reliability coefficient was 0.86. In current study, the Cronbach's alpha was 0.85 .

Objective measures of Facebook use included the number of Facebook friends (9-point scale, from 1-0-100 friends, to 9 - above 800 friends), hours spent using Facebook per week and using Facebook apps on a person's smartphone device.

\section{Procedure}

The data was collected between 2014 and 2019 among Polish Facebook users. Snowball sampling was used as a method of reaching a large group of respondents diverse in terms of social status, education level, Internet literacy, and mobile use proficiency. An electronic version of the questionnaires was sent to potential participants with a request to post the link on their Facebook walls. The questionnaires were also sent to Facebook users with a request to spread the message among their Facebook friends. The participants received no monetary reimbursement.

\section{Data analytic approach}

First, descriptive analysis of the characteristics of the FIQ items was conducted (i.e., mean, standard deviation, skewness, kurtosis, intercorrelations). Second, dimensionality of the FIQ via exploratory factor analysis (EFA) and confirmatory factor analysis (CFA) was examined. The total sample was randomly split into two samples; one was used for the EFA and the other for the CFA. CFA was based on the maximum likelihood method with Sattora-Bentler adjustment(Satorra \& Bentler, 1994). This adjustment was used because there was a violation of multivariate normal distribution (Doornik-Hansen omnibus test: $\chi_{(d f=16)}^{2}=12133.40, p<0.001$; Henze-Zirkler's consistent test: $\chi_{(d f=1)}^{2}=187000.00 ; p<0.001 ;$ Mardia's multivariate kurtosis test: $\chi^{2}(d f=1)=6232.64, p<$ 0.001 and Mardia's multivariate skewness test: $\left.\chi^{2}(d f=120)=10521.90, p<0.001\right)$. The following statistics were used to determine model fit: $\chi^{2}$, Root Mean Square Error of Approximation (RMSEA), Standardized Root Mean Square Residual (SRMR), comparative fit index (CFI), Tucker-Lewis index (TLI) ( Hu \& Bentler, 1999; Kline, 2011). RMSEA lower than 0.08 and SRMR lower than 0.08 indicates a good fit of the model. Also, values of CFI and TLI higher than 0.90 allow a conclusion that a model fits well to a data (Kline, 2011; Hu \& Bentler, 1999). Additionally, the unidimensionality of FIQ was further examined using different coefficients such as explained common variance (ECV), mean of item residual absolute loadings (MIREAL) and unidimensional congruence (Ferrando \& Lorenzo-Seva, 2018).

Third, an item responses theory (IRT) analysis which is concerned with development of test items and accurate test scoring (Hambleton \& Swaminathan, 2013) was used. EFA and CFAs are the most common techniques for evaluating the dimensionality of questionnaires. However, these analyses do not constitute an exhaustive analysis at the item-level. Therefore, we used item responses theory (IRT) analysis which is concerned with development of test items and accurate test scoring. Also, IRT analysis reflects more precisely the relationship between the underlying psychological construct being measured and the measurement process (Hambleton \& Swaminathan, 2013). 
The eight items were analyzed using the graded response model (GRM) which analyze ordinal responses and rating scales and where each response option level is compared to all response options above that level (Samejima, 1997). Specifically, if the FIQ has a 7-point response scale, from 1 - strongly disagree, to 7 - strongly agree, there is six comparisons between levels. Each comparison is described by threshold which indicates the location on theta ( $\theta$ ) at which individuals would be equally likely to indicate above and below comparison response levels. In this context, the theta $(\theta)$ reflects a unidimensional latent trait being assessed by the FIQ and has a mean of 0 and a standard deviation of 1 with an arbitrary range that will cover the latent trait that is being measured by this scale. The first threshold $\left(\beta_{1}\right)$ describe location on theta when individuals choosing to respond 1 versus all other responses. Similarly, the second threshold $\left(\beta_{2}\right)$ describe location on theta when individuals choosing to respond 1 or 2 versus all other responses. Other thresholds (i.e. $\beta_{3}$, $\beta_{4}, \beta_{5}, \beta_{6}$ ) are described analogously. The item discrimination parameter (a) reflects how well item identify individuals at different levels of the latent trait. This parameter has theoretical range from $-\infty$ to $+\infty$. However, items with negative values of $a$ and lower than 1 may considered problematic and consideration should be given to removing them from the scale (Hambleton \& Swaminathan, 2013) (Yang \& Kao, 2014). In addition, item response category characteristic curve (CCC) was used in order to analyse the eight items more accurately. The item response category characteristic curve presents the probability of individuals choose a certain response on the scale (1-7) at various levels of the Facebook intrusion latent trait.

Fourth, reliability analysis of the FIQ was conducted using Cronbach's alpha, composite reliability, factor determinacy (the correlation between the factor score estimates and true factor scores) and average variance extracted. For the above analyses, the total sample was used.

Fifth, construct validity was assessed. The relationships between FIQ score and Facebook Intensity Scale score, the Bergen Facebook Addiction Scale score, problematic Internet use and problematic video gaming which have been associated with behavioral addiction was assessed. The rho Spearman correlations coefficient and bootstrap method $(\mathrm{N}=5000 ; 95 \% \mathrm{Cl})$ was used to examine these relationships. Additionally, partial correlations was used to verify the separation between FIQ and problematic video gaming whilst controlling for problematic Internet use. The criterion validity of the FIQ was also analyzed using Multiple Indicator, Multiple Cause (MIMIC) model (Lee et al., 2013) including items-based latent construct of Facebook intrusion and predictors associated with objective Facebook-related behaviors indicated in previous studies: hours spent using Facebook per week, number of Facebook friends (9-point scale, from 1-0-100 friends, to 9 - above 800 friends) and using Facebook apps in smartphone (Salehan \& Negahban, 2013) (Kittinger et al., 2012) (Zheng \& Lee, 2012) (A. Błachnio et al., 2014). Also, bootstraping method (5000 sample) with bias-corrected percentile method was used to estimate a standardized regression weights, correlations and R-squared value with 95\% confidence interval (Byrne, 2010) (Kline, 2011). Taking into account that people who use psychoactive substances are also more likely to have behavioural addictions, such as social networking addiction (Thege et al., 2016) (Pawłowska et al., 2014) (Kuss \& Griffiths, 2011), comparisons between the addiction treatment group and the control group on the FIQ were tested. The t Student test was used to verify difference between groups in terms of the FIQ score, and Cohen's d was calculated as an effect size (Cohen, 1988). The difference between groups was also verified in terms of hours spent using Facebook per week, number of Facebook friends, hours spent using Internet per week, years of having a Facebook profile, and using Facebook apps on smartphone.

Sixth, FIQ normalization was developed. In this context, the standardized sten score was used (Coaley, 2014). Given sex and age differences (Atroszko et al., 2017) (A. Błachnio et al., 2015) (Agata Błachnio, Przepiorka, Bałakier, et al., 2016), we calculated norms based on subgroups samples. The age subgroups were separated due to the educational system in Poland (primary school: up to 15 years old; high school: 16-19 years old; college 20-24 years old). The FIQ score for each subgroups have values of skewness and kurtosis lower than 1, except for the three subgroups (men: 10-15 years; women: 30-39 years; men: 40 and above years) where these values were higher than 1 but lower than 1.2. Therefore, logarithmic data of FIQ score was performed using natural logarithm for these three groups before standardization. The statistical analyses were conducted using IBM SPSS Version 21 with AMOS 22 (descriptive statistics, criterion validation analysis), Stata 14 (CFA, IRT analysis) and Factor 10 (EFA, unidimensionality analysis).

\section{Results}

\section{Descriptive statistics}

The descriptive statistics including the mean, standard deviation, skewness and kurtosis for all items and the FIQ total score are presented in Table 1. Also, rho Spearman correlations coefficient between the items and between items and total score of FIQ are reported. Item-level correlations were between $0.27-0.59, p$ $<0.001$.

\section{Factor structure}

\section{Exploratory factor analysis}

The factor structure of the FIQ was investigated by performing an EFA (Sample $1 ; N=6375$ ) and CFA (Sample 2; $N=6378$ ). In the case of EFA, the Principal Axis Factoring extraction method with Promax rotation was used. Also, the scree plot (Cattell, 1966) and Kaiser (Kaiser, 1960) criterion was implemented to extract the number of components. The Kaiser-Meyer-Olkin Measure of Sampling Adequacy $(\mathrm{KMO}=0.903)$ and Bartlett's Test of Sphericity $\left(\mathrm{X}^{2}(28,6375)=\right.$ $18835.10 ; p<0.001$ ) confirmed the appropriateness for conducting the EFA (Hair et al., 2010). The EFA showed that a single factor explaining 51.58\% of the total variance of the Facebook intrusion construct was the best solution. Taking into account that the acceptable threshold of items was above 0.50 factor loadings (Ferguson \& Cox, 1993), all items fulfilled this criterion (see Table 2).

The ECV, defined as the proportion of common variance attributable to the general factor was 0.87 which was above the desired threshold of 0.85 . The MIREAL value was below the recommended threshold of 0.30 and equal 0.19 , indicating that the unidimensional solution had no substantial bias. Furthermore, the unidimensional congruence was 0.98 which was above the recommended threshold of 0.95 . Taken together, these results provide initial support for the Polish version of the FIQ as representing a unidimensional construct. 
A CFA based on the maximum likelihood method with Sattora-Bentler adjustment (Satorra \& Bentler, 1994) was applied to confirm the possible single factor solution of the FIQ. Overall, the one-factor structure of the FIQ had an acceptable model fit: $\chi^{2}(\mathrm{df}=20)=888.78, p<0.001 ; \mathrm{RMSEA}=0.083 ; \mathrm{SRMR}=0.038 ; \mathrm{CFI}=$ $0.943 ; \mathrm{TLI}=0.920$. However, the RMSEA was close to the 0.8 threshold ((Kline, 2011) (Hu \& Bentler, 1999)). Factor loadings for all items ranged from 0.574 to 0.740 (see Table 3).

Item response theory

Item location threshold values $(\beta)$ and item discrimination parameter $(\alpha)$ are outlined in Table 4.

In Figure 1, each curve in each plot represents the probability of endorsing a certain response level. In this context, black curve (solid line) reflects how the probability of choosing the first response level (i.e. strongly disagree) changes as a function of variations in theta (i.e. Facebook intrusion) level. This curve is higher at the lower end of the Facebook intrusion latent trait. This indicates that individuals with low Facebook intrusion tend to choose the first response level on this item. However, if the value of latent trait increases, the probability of choose the first response level decreases. At the same time, the probability of choosing the other response level increases. Hence, when Facebook intrusion is very high, individuals tend to choose the seventh response level (i.e. strongly agree). It is important to note that the curves peaking and dispersing across all of the latent trait indicate better discriminating between individuals by certain item (Hambleton \& Swaminathan, 2013) (Embretson \& Reise, 2013) (Jean-Pierre et al., 2014).

\section{Reliability analysis}

Cronbach's alpha of the FIQ was acceptable (0.86). Also, the reliability as measured by the composite reliability was 0.87 which is above the desired threshold of 0.70 (Nunnally, 1994). The factor determinacy was 0.93 . Considering that higher score of factor determinacy (range: 0-1) indicate higher levels of reliability and value above 0.80 are recommended, this value may indicate a good reliability of FIQ (Ferrando \& Lorenzo-Seva, 2018). Average variance extracted equal 0.45 which was below the recommended threshold of 0.50 . However, the convergent validity of the construct measured by average variance extracted is still adequate when composite reliability is higher than 0.6 (Fornell \& Larcker, 1981). Taken together, these results may suggest that the Polish version of the FIQ presents good internal consistency.

\section{Criterion-related validity}

The correlation between the FIQ score and Facebook Intensity Scale score showed a moderate to high positive correlation (rho = 0.75; $\mathrm{p}<0.001 ; 95 \% \mathrm{Cl}=0.71$, 0.78). The correlation between FIQ score and Bergen Facebook Addiction Scale scores were also moderate to high ( $\mathrm{rho}=0.75 ; p<0.001 ; 95 \% \mathrm{Cl}=0.68,0.80)$. In line with the previous findings (Kittinger et al., 2012) (Salehan \& Negahban, 2013) (Zheng \& Lee, 2012) (A. Błachnio et al., 2014), the results presented that Facebook intrusion was positively related with hours spent using Facebook per week $(\beta=0.38 ; p<0.001)$, number of Facebook friends $(\beta=0.24 ; p<0.001)$ and using Facebook apps on smartphone $(\beta=0.12 ; p<0.001)$. The MIMIC model presented with well fit to the data: $\chi^{2}$ (df $\left.=31\right)=57.91, p=0.002 ; \mathrm{RMSEA}=$ $0.032(90 \% \mathrm{Cl}=0.019,0.044) ; \mathrm{SRMR}=0.022 ; \mathrm{GFI}=0.988 ; \mathrm{CFI}=0.989 ; \mathrm{TLI}=0.981$.

The findings showed a significant positive correlation between the FIQ scores and Problematic Internet Use Test score (rho = 0.59; $\mathrm{p}<0.001 ; 95 \% \mathrm{Cl} 0.460 .70$ ) and the Problem Videogame Playing Questionnaire score (rho $=0.23 ; \mathrm{p}=0.009 ; 95 \% \mathrm{Cl} 0.050 .39$ ). When partial correlations were used to determine the relationship between FIQ and Problem Videogame Playing Questionnaire scores whilst controlling for Problematic Internet Use Test score, no statically significant relation between them was found (rho $=-0.12 ; p=0.192 ; 95 \% \mathrm{Cl}-0.290 .07$ ). The correlation between score of scales measured problematic Internet use and problematic video gaming was significant (rho $=0.53 ; \mathrm{p}<0.001 ; 95 \% \mathrm{Cl} 0.380 .66$ ).

The findings demonstrated that addiction group had higher FIQ scores than control group. There were no other differences between the analyzed groups (see Table 5).

\section{Normalization}

With the aim of enabling the application of the FIQ in the context of individual diagnostics, the normative data for the FIQ score norms have been reported (Table 6). The age subgroups were separated due to the educational system in Poland (primary school: up to 15 years old; high school: 16-19 years old; college 20-24 years old). The FIQ score for each subgroups have values of skewness and kurtosis lower than 1, except for the three subgroups (men: 10-15 years; women: 30-39 years; men: 40 and above years) where these values were higher than 1 but lower than 1.2. Therefore, logarithmic data of FIQ score was performed using natural logarithm for these three groups before standardization.

\section{Discussion}

This study presented the psychometric properties of a Polish adaptation of Facebook Intrusion Questionnaire. Consistent with previous research (Elphinston \& Noller, 2011), a unidimensional factor structure of the Polish version of the FIQ was supported in an EFA and CFA. The Polish version of the FIQ showed good internal consistency. The adapted FIQ also demonstrated adequate construct validity. It was associated with related constructs such as hours spent using Facebook per week, problem videogaming, Internet use and a secondary measure of Facebook addiction. Overall, these results suggest that the adapted FIQ is a valid and reliable measure of Facebook addiction, suitable for use in the Polish population.

Normative data were developed for use in Poland. The sampling procedure was applied to ensure reasonable representation of a cross-section of the population of Poland. The obtained test scores were similar to those of Australian norms (Elphinston \& Noller, 2011). Moreover, the results confirmed that each 
item had adequate discrimination and information levels, suggesting that Facebook intrusion could be discriminated against with high accuracy.

In line with the previous studies (Thege et al., 2016) (Pawłowska et al., 2014) (Kuss \& Griffiths, 2011), the findings also showed that addiction treatment group had higher FIQ scores than control group. These findings have implications for the importance of assessing behavioral addictions in those seeking addiction treatment, as Facebook addiction is not currently routinely assessed in AOD treatment service delivery models. Future epidemiological studies could examine prevalence rates in clinical populations.

The study has several limitations. The data were collected over a 5-year period. It is possible that normative patterns of Facebook usage changed over time. The outcome variables collected in this study were self-report. It will be important for future studies to corroborate the findings using other measures of Facebook use such as in diary studies. As the Polish citizens are a rather ethnically uniform group, we did not control for racial or ethnic status. Future studies could examine the differences in the areas of Poland where ethnicity is more diverse. We tested the validity of the FIQ in a Polish population. It will be important in future research to examine whether the FIQ is valid in other cultural contexts and to verify the cultural invariance. It would be also of value to verify whether this measure can be adapter for use in other types of social networking sites, such as Instagram or Twitter.

\section{Conclusion}

Overall, the Polish version of the FIQ appears to be a reliable and valid measure of problematic Facebook use. The study indicated that each item of the Polish version of the FIQ has appropriate discrimination ability and information and could discriminate at high accuracy Facebook excessive use. The findings are important for several reasons. Firstly, the FIQ can be used in different age groups and in treatment settings. Second, due to the fact that in Poland Facebook is the most popular networking sites (Szuba, 2020) the FIQ can be useful for psychologists, pedagogics, as well as for specialists working with people with problematic new media use.

\section{Declarations}

- Ethics approval and consent to participate

The study was approved by Ethical Committee of Institute of Psychology, The John Paul II Catholic University of Lublin (KEBN_13/2018)

- Consent for publication

Not applicable

- Availability of data and materials

The datasets during and/or analysed during the current study available from the corresponding author on reasonable request.

- Competing interests

The authors declare that they have no competing interests

- Funding

The study was financed by the National Science Centre, Poland, grant no. UMO-2017/25/B/HS6/01517

- Authors' contributions

A.B. devised the project, the main conceptual ideas, collecting the data, wrote the manuscript with input from all authors.

AP collecting the data, giving the comments to the paper in each stage of manuscript, writing paper

AC performer statistical analyses, description the results, giving the comments to the paper in each stage of manuscript, writing paper

RE giving the comments to the paper in each stage of manuscript, writing paper

- Acknowledgements

Not applicable

\section{References}

1. Andreassen, C. S., Torsheim, T., Brunborg, G. S., \& Pallesen, S. (2012). Development of a Facebook Addiction Scale. Psychological Reports, 110(2), 501517. https://doi.org/10.2466/02.09.18.PR0.110.2.501-517

2. Atroszko, A., Balcerowska, J. M., Bereznowski, P., Biernatowska, A., Pallesen, S., \& Schou, C. (2017). Facebook addiction among Polish undergraduate students: Validity of measurement and relationship with personality and well-being. Computers in Human Behavior, 85, 329-338.

https://doi.org/https://doi.org/10.1016/j.chb.2018.04.001

3. Bendayan, R., \& Blanca, M. J. (2019). Spanish version of the Facebook Intrusion Questionnaire (FIQ-S). Psicothema, 31(2), $204-209$. 
4. Błachnio, A., Przepiorka, A., Bałakier, E., \& Boruch, W. (2016). Who discloses the most on Facebook? Computers in Human Behavior, $55,664-667$. https://doi.org/10.1016/j.chb.2015.10.007

5. Błachnio, A., Przepiorka, A., Benvenuti, M., Cannata, D., Ciobanu, A. M., Senol-Durak, E., Durak, M., Giannakos, M. N., Mazzoni, E., Pappas, I. O., Popa, C., Seidman, G., Yu, S., Wu, A. M. S., \& Ben-Ezra, M. (2016). Cultural and Personality Predictors of Facebook Intrusion: A Cross-Cultural Study. Frontiers in Psychology, 7(February 2004), 1895. https://doi.org/10.3389/fpsyg.2016.01895

6. Błachnio, A., Przepiorka, A., Benvenuti, M., Mazzoni, E., \& Seidman, G. (2018). Relations Between Facebook Intrusion, Internet Addiction, Life Satisfaction, and Self-Esteem: a Study in Italy and the USA. International Journal of Mental Health and Addiction. https://doi.org/10.1007/s11469-018-0038-y

7. Błachnio, A., Przepiorka, A., \& Czuczwar, S. J. (2017). Type D personality, stress coping strategies and self-efficacy as predictors of Facebook intrusion. Psychiatry Research, 253(March), 33-37. https://doi.org/10.1016/j.psychres.2017.03.022

8. Błachnio, A., Przepiorka, A., \& Rudnicka, P. (2016). Narcissism and self-esteem as predictors of dimensions of Facebook use. Personality and Individual Differences, 90, 296-301. https://doi.org/10.1016/j.paid.2015.11.018

9. Błachnio, A., \& Przepiórka, A. (2018). Facebook intrusion, fear of missing out, narcissism, and life satisfaction: A cross-sectional study. Psychiatry Research, 259(November), 514-519. https://doi.org/10.1016/j.psychres.2017.11.012

10. Błachnio, A., Przepiórka, A., \& Hawi, N. (2014). The More I Use Facebook the Higher Risk of Being Addicted to It? Report from study. in review.

11. Błachnio, A., Przepiórka, A., \& Pantic, I. (2015). Internet use, Facebook intrusion, and depression: Results of a cross-sectional study. European Psychiatry, 2-5. https://doi.org/10.1016/j.eurpsy.2015.04.002

12. Błachnio, A., Przepiórka, A., Wołońciej, M., Bassam Mahmoud, A., Holdoš, J., \& Yafi, E. (2018). Loneliness, Friendship, and Facebook Intrusion. A Study in Poland, Slovakia, Syria, Malaysia, and Ecuador. Studia Psychologica, 6O(3), 183-194. https://doi.org/10.21909/sp.2018.03.761

13. Brailovskaia, J., \& Margraf, J. (2017). Facebook Addiction Disorder (FAD) among German students-A longitudinal approach. PLoS ONE, 12 (12), 1-15. https://doi.org/10.1371/journal.pone.0189719

14. Byrne, B. M. (2010). Multivariate applications series. Structural Equation Modeling with AMOS: Basic Concepts, Applications, and Programming (2nd Ed.). New York, NY, US: Routledge/Taylor \& Francis Group.

15. Cattell, R. B. (1966). The scree test for the number of factors. Multivariate Behavioral Research, 1(2), 245-276.

16. Coaley, K. (2014). An introduction to psychological assessment and psychometrics. Sage. https://doi.org/dx.doi.org/10.4135/9781446221556

17. Cohen, J. (1988). Statistical power analysis for the behavioural sciences. Hillsdale, NJ: erlbaum.

18. Ellison, N. B., Steinfield, C., \& Lampe, C. (2007). The Benefits of Facebook "Friends:" Social Capital and College Students' Use of Online Social Network Sites. Journal of Computer-Mediated Communication, 12(4), 1143-1168. https://doi.org/10.1111/j.1083-6101.2007.00367.x

19. Elphinston, R. A., \& Noller, P. (2011). Time to face it! Facebook intrusion and the implications for romantic jealousy and relationship satisfaction. Cyberpsychology, Behavior and Social Networking, 14(11), 631-635. https://doi.org/10.1089/cyber.2010.0318

20. Embretson, S. E., \& Reise, S. P. (2013). Item response theory. Psychology Press.

21. Facebook. (2020). Statistics. http://newsroom.fb.com/company-info/.

22. Ferguson, E., \& Cox, T. (1993). Exploratory factor analysis: A users' guide. International Journal of Selection and Assessment, 1(2), 84-94.

23. Ferrando, P. J., \& Lorenzo-Seva, U. (2018). Assessing the quality and appropriateness of factor solutions and factor score estimates in exploratory item factor analysis. Educational and Psychological Measurement, 78(5), 762-780.

24. Fornell, C., \& Larcker, D. F. (1981). Evaluating structural equation models with unobservable variables and measurement error. Journal of Marketing Research, 18(1), 39-50.

25. Griffiths, M. D. (2005). A "components" model of addiction within a biopsychosocial framework. Journal of Substance Use, 10(4), $191-197$.

http://www.academia.edu/429550/Griffiths_M.D._2005_._A_components_model_of_addiction_within_a_biopsychosocial_framework._Journal_of_Substan 197

26. Hair, J. F., Anderson, R. E., Babin, B. J., \& Black, W. C. (2010). Multivariate data analysis: A global perspective (Vol. 7). Upper Saddle River, NJ: Pearson.

27. Hambleton, R. K., \& Swaminathan, H. (2013). Item response theory: Principles and applications. Springer Science \& Business Media.

28. Hawi, N. S., Blachnio, A., \& Przepiorka, A. (2015). Polish validation of the Internet Addiction Test. Computers in Human Behavior, 48, 548-553. https://doi.org/10.1016/j.chb.2015.01.058

29. Hu, L. T., \& Bentler, P. M. (1999). Cutoff criteria for fit indexes in covariance structure analysis: Conventional criteria versus new alternatives. Structural Equation Modeling, 6(1), 1-55. https://doi.org/10.1080/10705519909540118

30. Jean-Pierre, P., Cheng, Y., Paskett, E., Shao, C., Fiscella, K., \& Winters, P. (2014). Item Response Theory Analysis of the Patient Satisfaction with CancerRelated Care Measure: A Psychometric Investigation in A Multicultural Sample of 1,296 Participants. Support Care Cancer, 22(8), $2229-2240$.

https://doi.org/10.1007/s00520-014-2202-7.Item

31. Kaiser, H. F. (1960). The application of electronic computers to factor analysis. Educational and Psychological Measurement, 20(1), 141-151.

32. King, D. L., Haagsma, M. C., Delfabbro, P. H., Gradisar, M., \& Grif, M. D. (2013). Clinical Psychology Review Toward a consensus de fi nition of pathological video-gaming: A systematic review of psychometric assessment tools. 33, 331-342. https://doi.org/10.1016/j.cpr.2013.01.002

33. Kittinger, R., Correia, C. J., Ph, D., Irons, J. G., \& Ph, D. (2012). Relationship Between Facebook Use and Problematic. Cyberpsychology, Behavior and Social Networking, 15(6), 324-327. https://doi.org/10.1089/cyber.2010.0410

34. Kline, R. B. (2011). Principles and practice of structural equation. Modeling.(3nd. 
35. Kuss, D. J., \& Griffiths, M. D. (2011). Online social networking and addiction-a review of the psychological literature. International Journal of Environmental Research and Public Health, 8(9), 3528-3552. https://doi.org/10.3390/ijerph8093528

36. Lee-Won, R. J., Herzog, L., \& Park, S. G. (2015). Hooked on Facebook: The Role of Social Anxiety and Need for Social Assurance in Problematic Use of Facebook. Cyberpsychology, Behavior, and Social Networking, 18(10), cyber.2015.0002. https://doi.org/10.1089/cyber.2015.0002

37. Lee, N., Cadogan, J. W., \& Chamberlain, L. (2013). The MIMIC model and formative variables: problems and solutions. AMS Review, 3(1), 3-17.

38. Nunnally, J. C. (1994). Psychometric theory 3E. Tata McGraw-Hill Education.

39. Pawłowska, B., Zygo, M., Potembska, E., Kapka-skrzypczak, L., \& Dreher, P. (2014). Psychoactive substances use experience and addiction or risk of addiction among by Polish adolescents living in rural and urban areas. Annals of Agricultural and Environmental Medicine, 21(4), 776-782.

https://doi.org/10.5604/12321966.1129932

40. Saeed Abbasi, I. (2018). The Link Between Romantic Disengagement and Facebook Addiction: Where Does Relationship Commitment Fit In? American Journal of Family Therapy, 46(4), 375-389. https://doi.org/10.1080/01926187.2018.1540283

41. Salehan, M., \& Negahban, A. (2013). Social networking on smartphones: When mobile phones become addictive. Computers in Human Behavior, 29(6), 2632-2639. https://doi.org/10.1016/j.chb.2013.07.003

42. Samejima, F. (1997). Graded response model. In Handbook of modern item response theory (pp. 85-100). Springer.

43. Satorra, A., \& Bentler, P. M. (1994). Corrections to test statistics and standard errors in covariance structure analysis.

44. Szuba, M. (2020). Facebook users in Poland.

45. Tejeiro, R. A., Espada, J. P., Gonzálvez, M. T., \& Christiansen, P. (2015). Psychometric properties of the Problem Video Game Playing scale in adults Propriétés psychométriques de I 'échelle Problem Video Game Playing chez les adultes. Revue Europeenne de Psychologie Appliquee, 66(1), 9-13. https://doi.org/10.1016/j.erap.2015.11.004

46. Thege, B. K. Ÿ., Hodgins, D. C., \& Wild, T. C. (2016). Co-occurring substance-related and behavioral addiction problems: A person-centered, lay epidemiology approach. Journal of Behavioral Addictions, 5(4), 614-622. https://doi.org/10.1556/2006.5.2016.079

47. Yang, F. M., \& Kao, S. T. (2014). Item response theory for measurement validity. Shanghai Archives of Psychiatry, 26(3), $171-177$. https://doi.org/http://dx.doi.org/10.3969/j.issn.1002-0829.2014.03.010

48. Zheng, X., \& Lee, M. K. O. (2012). Computers in Human Behavior Excessive use of mobile social networking sites: Negative consequences on individuals. Computers in Human Behavior, 65(2016), 65-76. https://doi.org/10.1016/j.chb.2016.08.011

\section{Tables}

Table 1. Descriptive statistics and correlation between eight items of FIQ ( $N=12753)$.

\begin{tabular}{|c|c|c|c|c|c|c|c|c|c|c|c|c|}
\hline Items & M & SD & Skewness & Kurtosis & FIQ 1 & FIQ 2 & FIQ 3 & FIQ 4 & FIQ 5 & FIQ 6 & FIQ 7 & FIQ 8 \\
\hline FIQ 1 & 2.41 & 1.54 & 1.12 & 0.60 & & & & & & & & \\
\hline FIQ 2 & 4.31 & 1.92 & -0.26 & -1.08 & 0.43 & & & & & & & \\
\hline FIQ 3 & 1.98 & 1.48 & 1.62 & 1.89 & 0.47 & 0.27 & & & & & & \\
\hline FIQ 4 & 2.70 & 1.86 & 0.82 & -0.55 & 0.52 & 0.45 & 0.45 & & & & & \\
\hline FIQ 5 & 3.50 & 1.90 & 0.22 & -1.10 & 0.43 & 0.41 & 0.33 & 0.45 & & & & \\
\hline FIQ 6 & 3.19 & 1.97 & 0.48 & -1.03 & 0.47 & 0.51 & 0.41 & 0.54 & 0.48 & & & \\
\hline FIQ 7 & 2.02 & 1.52 & 1.57 & 1.69 & 0.51 & 0.30 & 0.49 & 0.53 & 0.41 & 0.47 & & \\
\hline FIQ 8 & 2.50 & 1.74 & 1.01 & -0.03 & 0.50 & 0.43 & 0.45 & 0.55 & 0.41 & 0.58 & 0.59 & \\
\hline FIQ total score & 22.61 & 10.02 & 0.62 & -0.09 & 0.71 & 0.70 & 0.61 & 0.77 & 0.70 & 0.79 & 0.68 & 0.76 \\
\hline
\end{tabular}

*All correlations were significant, $p<0.001$.

Table 2. The exploratory factor analysis of the Facebook Intrusion Questionnaire $(N=6375)$. 


\begin{tabular}{|c|c|c|c|}
\hline \multirow[t]{2}{*}{ Items } & \multirow[t]{2}{*}{ Factor loadings } & \multicolumn{2}{|c|}{ Communalities } \\
\hline & & Initial & Extraction \\
\hline 1. I often think about Facebook when I am not using it. & 0.702 & 0.437 & 0.493 \\
\hline 2. I often use Facebook for no particular reason. & 0.578 & 0.347 & 0.334 \\
\hline 3. Arguments have arisen with others because of my Facebook use. & 0.590 & 0.336 & 0.348 \\
\hline 4. I interrupt whatever else I am doing when I feel the need to access Facebook. & 0.731 & 0.455 & 0.535 \\
\hline 5. I feel connected to others when I use Facebook. & 0.604 & 0.327 & 0.365 \\
\hline 6. I lose track of how much I am using Facebook. & 0.712 & 0.463 & 0.507 \\
\hline 7. The thought of not being able to access Facebook makes me feel distressed. & 0.681 & 0.445 & 0.464 \\
\hline 8. I have been unable to reduce my Facebook use. & 0.735 & 0.480 & 0.540 \\
\hline Eigenvalue & & & 4.126 \\
\hline Total Variance Explained & & & $51.58 \%$ \\
\hline
\end{tabular}

Table 3. The confirmatory factor analysis results obtained from the eight items of the FIQ $(N=6378)$.

\begin{tabular}{|lll|}
\hline Items & Factor loadings & $\mathrm{p}$ \\
\hline 1. I often think about Facebook when I am not using it. & 0.698 & 0.001 \\
\hline 2. I often use Facebook for no particular reason. & 0.594 & 0.001 \\
\hline 3. Arguments have arisen with others because of my Facebook use. & 0.574 & 0.001 \\
\hline 4. I interrupt whatever else I am doing when I feel the need to access Facebook. & 0.737 & 0.001 \\
\hline 5. I feel connected to others when I use Facebook. & 0.601 & 0.001 \\
\hline 6. I lose track of how much I am using Facebook. & 0.725 & 0.001 \\
\hline 7. The thought of not being able to access Facebook makes me feel distressed. & 0.687 & 0.001 \\
\hline 8. I have been unable to reduce my Facebook use. & 0.740 & 0.001 \\
\hline
\end{tabular}

Table 4. Item statistics for the graded response model across all items of the Polish FIQ $(N=12753)$

\begin{tabular}{|llllllll|}
\hline Items & $a$ & $\beta_{1}$ & $\beta_{2}$ & $\beta_{3}$ & $\beta_{4}$ & $\beta_{5}$ & $\beta_{6}$ \\
\hline FIQ 1 & 2.06 & -0.41 & 0.43 & 1.01 & 1.54 & 2.09 & 2.63 \\
\hline FIQ 2 & 1.47 & -1.87 & -1.13 & -0.56 & 0.00 & 0.74 & 1.58 \\
\hline FIQ 3 & 1.70 & 0.26 & 0.97 & 1.41 & 1.87 & 2.46 & 3.07 \\
\hline FIQ 4 & 2.34 & -0.28 & 0.25 & 0.64 & 1.02 & 1.53 & 2.07 \\
\hline FIQ 5 & 1.50 & -1.21 & -0.48 & 0.07 & 0.70 & 1.42 & 2.22 \\
\hline FIQ 6 & 2.18 & -0.71 & -0.07 & 0.34 & 0.75 & 1.25 & 1.79 \\
\hline FIQ 7 & 2.34 & 0.21 & 0.80 & 1.18 & 1.61 & 2.08 & 2.51 \\
\hline FIQ 8 & 2.52 & -0.18 & 0.38 & 0.77 & 1.22 & 1.66 & 2.15 \\
\hline
\end{tabular}

Table 5. Difference between addiction and control group. 


\begin{tabular}{|lllllllll|}
\hline Variables & \multicolumn{2}{l}{ Addiction group } & \multicolumn{2}{l}{ Control group } & t & $\mathrm{p}$ & Cohen's d \\
\cline { 2 - 8 } & $\mathrm{M}$ & $\mathrm{SD}$ & $\mathrm{M}$ & $\mathrm{SD}$ & & & \\
FIQ score & 24.81 & 13.41 & 16.53 & 6.61 & 3.80 & $<0.001$ & 0.78 \\
\hline Facebook hours per week & 58.62 & 49.20 & 54.20 & 43.94 & 1.27 & 0.206 & - \\
\hline Internet hours per week & 40.15 & 53.10 & 27.97 & 38.51 & 0.46 & 0.647 & - \\
\hline Years of Facebook profile & 6.28 & 5.36 & 6.33 & 2.30 & -0.06 & 0.950 & - \\
\hline Number of Facebook friends & 5.04 & 2.33 & 5.13 & 2.53 & -0.17 & 0.866 & - \\
\hline Facebook apps use & 0.91 & 0.28 & 0.89 & 0.31 & 0.35 & 0.729 & - \\
\hline Age & 20.32 & 4.07 & 20.36 & 4.01 & -0.05 & 0.959 & - \\
\hline
\end{tabular}

Table 6. Normative data from the Polish general population ( $\mathrm{N}=12753)$ for the Facebook Intrusion Scale (sum score) in subgroup (gender, age).

\begin{tabular}{|c|c|c|c|c|c|c|}
\hline \multicolumn{7}{|l|}{ Women } \\
\hline \multirow[t]{3}{*}{ Sten score } & \multicolumn{6}{|l|}{ Age } \\
\hline & $10-15$ & $16-19$ & $20-24$ & $25-29$ & $30-39$ & $40+$ \\
\hline & $(\mathrm{N}=458)$ & $(\mathrm{N}=3104)$ & $(\mathrm{N}=3848)$ & $(\mathrm{N}=531)$ & $(\mathrm{N}=279)$ & $(\mathrm{N}=232)$ \\
\hline $1-3$ & -11 & -13 & -14 & -12 & -10 & 8 \\
\hline \multicolumn{7}{|l|}{ low } \\
\hline $4-7$ & $12-33$ & $14-34$ & $15-33$ & 13-31 & $11-28$ & $9-26$ \\
\hline \multicolumn{7}{|l|}{ average } \\
\hline $8-9$ & $34-44$ & $35-44$ & $34-43$ & $32-41$ & $29-46$ & $27-33$ \\
\hline \multicolumn{7}{|l|}{ high } \\
\hline 10 & $45-$ & $45-$ & $44-$ & $42-$ & $47-$ & $34-$ \\
\hline \multicolumn{7}{|l|}{ very high } \\
\hline \multicolumn{7}{|l|}{ Men } \\
\hline \multirow[t]{3}{*}{ Sten score } & Age & & & & & \\
\hline & $10-15$ & $16-19$ & $20-24$ & $25-29$ & $30-39$ & $40+$ \\
\hline & $(N=388$ & $(\mathrm{N}=1615)$ & $(\mathrm{N}=1551)$ & $(\mathrm{N}=315$ & $(N=211)$ & $(\mathrm{N}=221)$ \\
\hline $1-3$ & -9 & -12 & -12 & -10 & -9 & -9 \\
\hline \multicolumn{7}{|l|}{ low } \\
\hline $4-7$ & $10-28$ & $13-30$ & $13-30$ & $11-29$ & $10-32$ & $10-24$ \\
\hline \multicolumn{7}{|l|}{ average } \\
\hline $8-9$ & $29-49$ & $31-40$ & $31-40$ & $30-39$ & $33-44$ & $25-41$ \\
\hline \multicolumn{7}{|l|}{ high } \\
\hline 10 & $50-$ & $41-$ & $41-$ & $40-$ & $45-$ & $42-$ \\
\hline very high & & & & & & \\
\hline
\end{tabular}

\section{Figures}



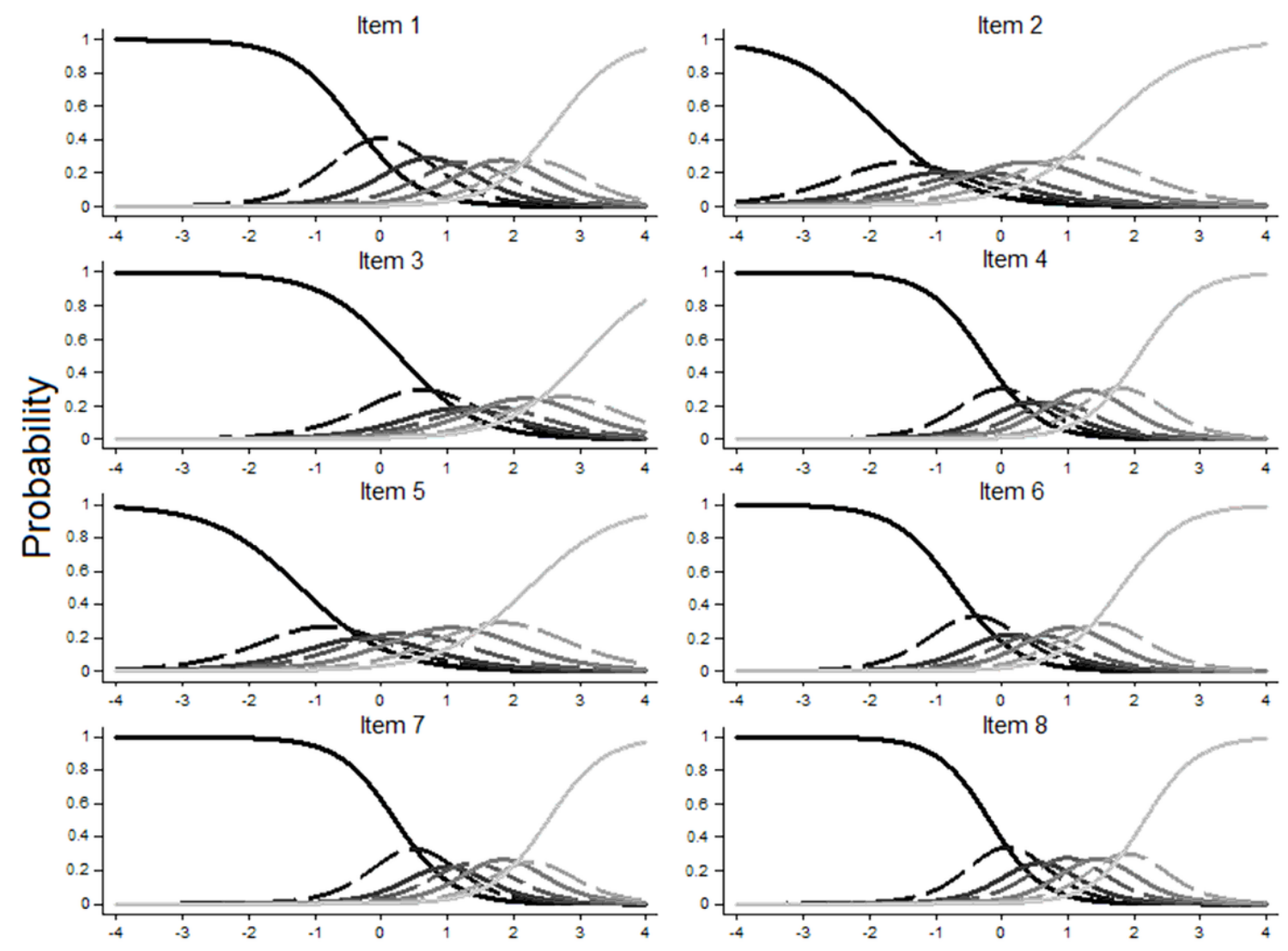

\section{Theta}

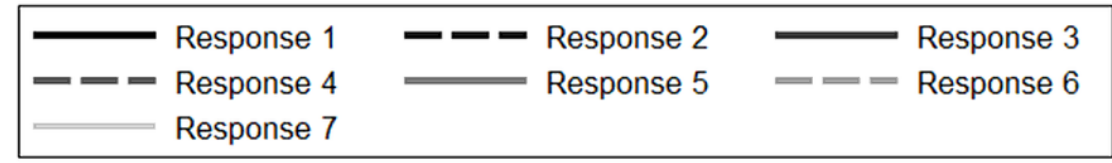

\section{Figure 1}

Item Response Category Characteristic Curves (CCC) for the eight items. 


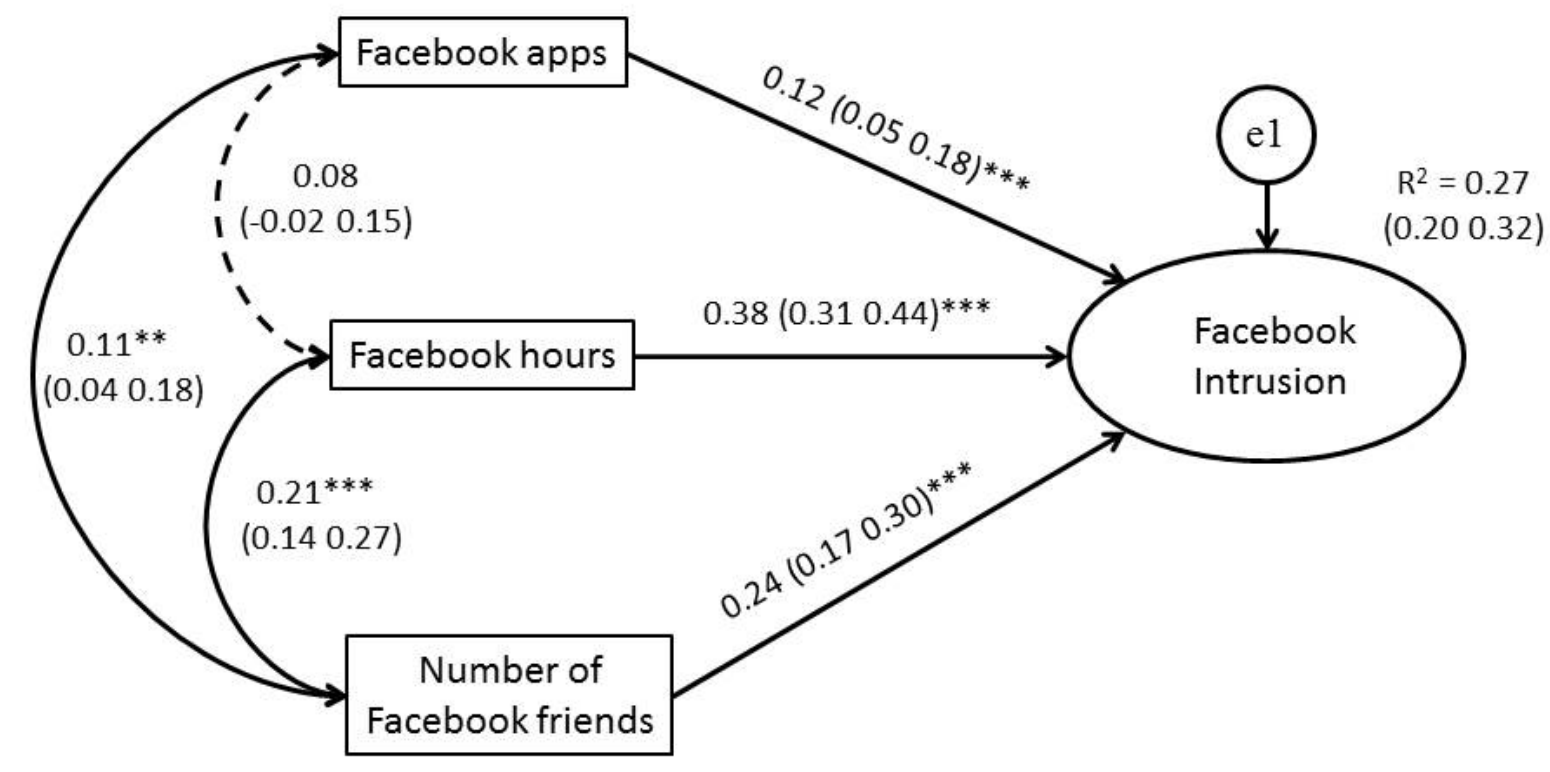

${ }^{*} \mathrm{p}<0.05 ;{ }^{* *} \mathrm{p}<0.01 ;{ }^{* * *} \mathrm{p}<0.001$

Figure 2

MIMIC model predicting overall Facebook Intrusion scores by hours spent using Facebook per week, number of Facebook friends and using smartphone Facebook apps $(\mathrm{N}=857)$. 